\title{
Endoscopic therapy with argon plasma for radiation proctitis: factors associated to the number of therapeutic sessions
}

\begin{abstract}
Introduction: Radiation proctitis appears as a result of radiotherapy. Argon plasma therapy (APC) is an option for its treatment.

Objective: To describe the results of APC therapy on the radiation proctitis and factors associated to the number of sessions to achieve resoluteness of bleeding.

Method: An observational study was performed in 38 patients who suffering from radiaton proctitis and rectorrhaegy, who received a treatment with APC untill cessation of bleeding and the improvement of their haemoglobin and later follow-up treatment, to 6 and 12 months of it, in the endoscopy Unit, from 2012 to 2015. Values of mean and percentage were calculated; different statistical tests were used to evaluate association between some variables.

Results: The mean age was 62.1 (range 30-83)years, female group and cervix cancer predominated in $34(89.5 \%)$ and $27(71.7 \%)$ patients, with a mean of 30.5 radiation sessions (range 21-42) and a mean of 9.9 months (range 3-24) to start post-radiation bleeding, 18 (47.4\%) sick had severe bleeding. The mean hemoglobin was $9.5 \mathrm{~g} / \mathrm{dl}$ (5.4 to 13.8$)$ and 12 cases $(31.6 \%)$ required transfusion. Grade $\mathrm{C}$ of proctitis, $\leq 10 \mathrm{~cm}$ of extension and $\leq 50 \%$ of mucosa affected were prevailed in $18(47.4 \%), 20$ (52.6\%) and $25(65.8 \%)$ cases respectively; $50 \%$ of cases had friability. The mean therapeutic sessions to resolution of bleeding was 3.1 (range 1-8). Mean hemoglobin after APC therapy increased to $11.4(\mathrm{p}<0.05)$. A higher number of therapeutic sessions was associated with the highest percentage of affected circumferential mucosa $(\mathrm{p}=0.012)$. Proctalgia was found in $2(5.3 \%)$ patients.
\end{abstract}

Conclusion: APC is a good therapy for radiation proctitis with resolution of bleeding and the improvement of haemoglobin using less therapeutic sessions and few complications. The highest percentage of mucosa circumferentially affected with lesions influences the need to apply a greater number of therapeutic sessions.

Keywords: radiation proctitis, rectal bleeding, argon plasma, endoscopy therapeutic with argon plasma
Volume 8 Issue 2 - 2017

\author{
Elizabeth Montes de Oca Megías,' Maricela \\ Morera Pérez, ${ }^{2}$ Guillermo Noa Pedroso, ${ }^{3}$ \\ Julián Francisco Ruiz Torres,' Raúl Brizuela \\ Quintanilla,' Jorge Luis García Menocal' \\ 'Gastroenterology and Digestive Endoscopy Department, \\ National Center for Minimal Access Surgery, Cuba \\ ${ }^{2}$ Department of Research and Biostatistcs, National Center for \\ Minimal Access Surgery, Cuba \\ ${ }^{3}$ Department of Gastroenterology and Digestive Endoscopy \\ Department, Hermanos Ameijeiras Hospital, Cuba
}

Correspondence: Elizabeth Montes de Oca Megías, National Center for Minimal Access Surgery, Párraga between San Mariano and Vista Alegre. Diez de Octubre, Havana, Cuba, Email 78elizabetmm@gmail.com

Received: June 16, 2017| Published: December 13, 2017

\section{Introduction}

Today oncologic diseases show an increase in their incidence and prevalence. ${ }^{1}$ Adverse effects or complications of the treatments channeled into cure or improvement of people who suffered from these diseases, may be very serious with deterioration in the quality of life of these people. The chronic radiation proctitis is an example which appears as a result of a radiotherapy implemented on a pelvic malignancy. ${ }^{2,3}$ They appear at three months after radiotherapy, ${ }^{2-4}$ till 31years later ${ }^{5}$ and have reported an incidence between 2-20\%., ${ }^{3,4}$

Physiopathologically, it is the result of endarteritis obliterans of submucosal arterioles, with consequent ischemia, submucosal fibrosis and formation of new vessels (telangiectasia), which produces a chronic, progressive and permanent damage to the vasculature of the stromal tissue of rectal wall. ${ }^{3,4,6}$ The most common form of expression is rectorrhaegy, which occurs in $72 \%$ of patients. ${ }^{2-5}$ There are many therapeutic options for chronic radiation proctitis, such as: topical treatment with aminosalicylates, steroids, sucralfate, short chain fatty acids enemas ${ }^{7-9}$ and formalin by direct instillation or endoscopic application. ${ }^{10-12}$ Antioxidants ${ }^{2,9}$ and hyperbaric oxygenation can be used too. All therapies with their specific impact in effectiveness and adverse effects. ${ }^{13-15}$ Diverse endoscopic techniques have been used with varying results, sucha as: the bipolar electrocoagulation, the heat probe and the laser with some benefits, but frequent complications. ${ }^{2,6,7,16}$ The argon plasma coagulation (APC) has shown the well-recognized utility due to its effectiveness in the bleeding resolution and advantages over the rest of termic therapy due to easy use, less complication and relatively inexpensive. , $, 6,-9,17,18^{\text {The }}$ National Center for Minimal Access Surgery is the unique institution in Cuba that achieved a great experience in this therapeutic modality. That is why this group of specialists described the results of the Argon plasma coagulation (APC) implementation in the chronic radiation proctitis and the factors associated with the number of sessions to achieve the bleeding resoluteness.

\section{Materials and methods}

An observational study was made to describe the results of the endoscopic APC therapy in patients with chronic radiation proctitis and rectorrhaegy, as well as the factors associated to the number of sessions to achieve the bleeding resoluteness in the National Center for Minimal Access Surgery, Havana, Cuba from 2012 to 2015. The universe is made up of patients diagnosed with chronic radiation proctitis confirmed by colonoscopy that meet the selection criteria. The sample consisted of 38 patients from the Oncology Services of other institutions and who were treated in our hospital during the study period. 


\section{Inclusion criteria}

i. Patients aged $\geq 18$ years.

ii. A period $\geq 3$ months of completion of radiotherapy.

iii. Colonoscopic diagnosis of vascular pattern characteristic of radiation proctitis and rectal bleeding.

\section{Exclusion criteria}

i. Patients who refuse to participate in the research.

ii. Unclear endoscopic lesions or coexistence of other causes of rectal bleeding or anemia (inflammatory, vascular or neoplastic lesions).

iii. To present associated diseases, which induce potentially anemia (cirrhosis, HIV, inflammatory bowel disease).

iv. Neoplastic lesion and / or metastasis.

v. Non compliance of surveillance protocol.

To collect the data, schedule was made and there was emptied the information obtained from the interview, the clinical history of patients and Endosorex data base. The investigation took into account demographic variables such as age and sex; personal records about associated microvascular diseases (Arterial Hypertension, diabetes mellitus, ischemic Cardiopathy and congestive heart failure), the motive of radiation (the location of the malignant lesion that was irradiated), the number of radiation sessions and the beginning of post-radiation bleeding (time in months from the end of treatment with radiation and the onset of rectal bleeding).

The clinical and laboratory variables were also considered. The intensity of the rectal bleeding was graded into three groups (based on Chutkan classification): mild bleeding (low rectal bleeding on paper to clean), Moderate bleeding (bleeding into the toilet bowel), Severe bleeding (severe bleeding even staining the clothes and bleeding with transfusion requirement). The frequency was measured: daily, frequently (at least 3times a week or more) and occasional (less than 3times a week) as well as the appearance of the bleeding (spontaneous with defecation or both). Besides, it was necessary to take into account the initial level of haemoglobin of the patients, and if some of them had the necessity to be transfused. For the analysis of the endoscopic variables before APC therapy, the extension of the injury was taking into account (more than $10 \mathrm{~cm}$ or $\leq 10 \mathrm{~cm}$ ). Also, the percentage of affected mucosa (more than $50 \%$ or $\leq 50 \%$ ) and the friability (presence or absence of this sign) were collected.

According to Saunder's score (taking from Zinicola R) three previous parameters were related through an accumulative points which determined the category of endoscopic severity of radiation proctitis into three grades: A. (Mild- 2 points), B. (Moderate- 3 points), C. (Serious- $4 / 5$ points).

\begin{tabular}{|c|c|c|c|}
\hline Parameter & & & Points \\
\hline $\begin{array}{l}\text { Distribution of } \\
\text { telangectasias }\end{array}$ & $\begin{array}{l}\text { I. } \\
2 .\end{array}$ & $\begin{array}{l}\text { Distal Rectum }<10 \mathrm{~cm} \\
\text { from anal edge } \\
>10 \mathrm{~cm} \text { from anal edge }\end{array}$ & $\begin{array}{l}1 \mathrm{p} \\
2 \mathrm{p}\end{array}$ \\
\hline $\begin{array}{l}\text { Surface covered by } \\
\text { telangectasias }\end{array}$ & $\begin{array}{l}\mathrm{I} . \\
2 .\end{array}$ & $\begin{array}{l}\text { Less than } 50 \% \\
\text { More than } 50 \%\end{array}$ & $\begin{array}{l}1 \mathrm{p} \\
2 \mathrm{p}\end{array}$ \\
\hline $\begin{array}{l}\text { Presence of fresh } \\
\text { blood }\end{array}$ & I. & No existence & 0 \\
\hline
\end{tabular}

When finished the endoscopic therapy and during its follow-up treatment, other variables were taking into account as the number of sessions needed by patients to achieve resolution of bleeding, the immediate and late complications derived from endoscopic therapy (pain, urgency, colon explosion, rectal strictures, deep ulcers and necrosis), values of haemoglobin after endoscopic therapy and rebleeding.

\section{Endoscopic techniques and procedures}

Before the beginning of implementation of any procedure, an adequate bowel preparation (liquid regimen and the consumption of magnesium sulfate $33 \%, 120 \mathrm{ml}$ at $7.00 \mathrm{am}$ and $120 \mathrm{ml}$ at $4.00 \mathrm{pm}$ ) was indicated the day before the procedure and informed consent was provided. The treatment was made by previous sedative with Propofol. Olympus Video-colonoscopy was employed and frontal flexible probe ERBE was introduced through channel of colonoscopy to administrate argon gas, connected to ERBE APC 300 German equipment. It has an argon gas flow fixed in $2 \mathrm{~L} / \mathrm{min}$ with a 50 watt potency. The argon was applied using the technique of stippling directly on telangiectasia, starting for the active bleeding and disposed proximal to the distal sections. Each session was made between a quarter and the half of a circumference and with interval between sessions of three weeks, until resolution of the clinical bleeding. When the patient reported clinically cessation of bleeding, the treatment stopped and the follow-up was made to 1, 6 and 12months, all clinic evolution and haematological data were collected.

\section{Statistical analysis}

The statistic program SPSS v.11.5 for Windows was used to elaborate and process the investigation database. Summary measures were used according to the type of variables (Media-range for quantitive variables, and percentages for qualitative variables). The data were expressed in tabular form. The statistical comparison of means (paired Student $t$ ) was made to measure initial and final patients' haemoglobin. Another useful test was the Spearman correlation bivariable test to evaluate the relation between haemoglobin and the number of radiation sessions with the number of therapeutic sessions of APC.

The Kruskal Wallis test was used to evaluate the association between the degree of bleeding and the grade of proctitis with the number of therapeutic sessions. The nonparametric Wilcoxon-MannWitney test was used to contrast the variables in the injure extension in centimeters $(\mathrm{cms})$, percentage of the circumference affected and the presence of friability with the number of therapeutic sessions of argon plasma received. The level of statistic signification $\alpha=0.05$ was measured to guarantee a $95 \%$ of fiability of the statistical tests used.

\section{Ethic aspects}

To carry out the research took into account the voluntary patient through informed consent, as well as to carry out the treatment with Argon Plasma. The authors of investigations proceeded with the strictest sense of the confidentiality of research data, respecting the ethical standards for the management of patient information.

\section{Results}

Table 1 shows the demographic characteristics and personal history of patients before endoscopic therapy. The mean age was 62.1years old (range $30-83$ ). 89,5\% of patients was female. Regarding the patient's personal history before endoscopic therapy, there was observed as the half of the sample did not have any pathological condition 
associated; in the group with diseases of the microvasculature, arterial hypertension and diabetes mellitus were the most represented with 10 $(26.3 \%)$ and $4(10.5 \%)$ patients respectively.

Cervical-uterine cancer was the most frequently associated cancer disease (27 cases for $71.1 \%$ ), followed by endometrial and prostate cancer, both with 4 cases $(10.5 \%)$. The Mean of radiation sessions was 30.5 (range between 21-42 sessions) and the beginning of bleeding episodes occurred between 3 and 24 months after completion of radiotherapy with a mean of 9.9 months (Table 1). The clinical, analytical and endoscopic aspects are shown in Table 2 . The bleeding of severe intensity appears in 18 cases $(47.4 \%)$, daily bleeding and spontaneous episodes were referred by $23(60.5 \%)$ and 18 cases $(47.4 \%)$ respectively.
The haemoglobin mean was of $9.5 \mathrm{~g} / 1$ and the transfusion requirement was described in 12 patients $(31.6 \%)$. The grade $\mathrm{C}$ of proctitis was prevailed in 18 patients to $47.4 \%$, the injuries with an extension less or equal to $10 \mathrm{cms}$ were detected in $52.6 \%$ of the cases and in 13 cases $(34.2 \%)$ more than $50 \%$ of the circumference rectal was affected $(13-34.2 \%) .50 \%$ of patients showed mucosal friability.

A total of 105 sessions were made to achieve the bleeding resolution with a mean of 3.1 sessions per patient. The rank varies between 1-8 interventions. The majority of patients (16 and 11) received 2 and 3 sessions of APC respectively (Table 3 ). Only 2 patients (5.3\%) had post-treatment proctalgy during the first sessions. One of them selflimited his treatment and the other needed the administration of oral analgesia.

Table I Demographic variables and personal history of the patient before endoscopic therapy

\begin{tabular}{|c|c|c|c|}
\hline \multicolumn{3}{|l|}{ Demographic Variables $(n=38)$} & Frequency \\
\hline \multirow[t]{2}{*}{ Age(years) } & \multirow{2}{*}{\multicolumn{2}{|c|}{ Mean (range) }} & $62, I(30-83)$ \\
\hline & & & Num. (\%) \\
\hline \multirow[t]{2}{*}{ Sex } & Male & & $4(10,5 \%)$ \\
\hline & Female & & $34(89,5 \%)$ \\
\hline \multirow{8}{*}{$\begin{array}{l}\text { Previous medical history of the patient before endoscopic } \\
\text { therapy. }(n=38) \\
\text { Associated Diseases }\end{array}$} & & & Num. (\%) \\
\hline & Non existence & & $19(50 \%)$ \\
\hline & Microvascular diseases & & \\
\hline & & Hypertension & $10(26,3 \%)$ \\
\hline & & Diabetes & $4(10,5 \%)$ \\
\hline & & Squeamish cardiopathy & $3(7,9 \%)$ \\
\hline & & Chronic heart Failure & I (2,6\%) \\
\hline & Others & & $5(13,2 \%)$ \\
\hline \multirow[t]{7}{*}{ Motive of radiation (Malignancies) } & Cérvical uterine & & $27(7 /, 1 \%)$ \\
\hline & Endometrial & & $4(10,5 \%)$ \\
\hline & Prostate & & $4(10,5 \%)$ \\
\hline & Rectum & & I $(2,6 \%)$ \\
\hline & Anus & & I $(2,6 \%)$ \\
\hline & Chordoma & & I $(2,6 \%)$ \\
\hline & & & Mean (Range) \\
\hline Number of sessions of radiation & & & $30,5(21-42)$ \\
\hline Beginning of post radiation bleeding (months) & & & $9,9(3-24)$ \\
\hline
\end{tabular}

Table 2 Clinical, analytical and endoscopic variables before endoscopic therapy

\begin{tabular}{|c|c|c|}
\hline \multicolumn{2}{|l|}{ Clinical Variables( $n=38)$} & \multirow{2}{*}{$\begin{array}{l}\text { Num. (\%) } \\
5(13,2 \%)\end{array}$} \\
\hline \multirow{4}{*}{ Rectal bleeding } & Mild & \\
\hline & Moderate & $15(39,5 \%)$ \\
\hline & Severe & $18(47,4 \%)$ \\
\hline & Daily & $23(60,5 \%)$ \\
\hline \multirow[t]{3}{*}{ Frequency } & Frequent & II (28,9\%) \\
\hline & Occasional & $4(10,5 \%)$ \\
\hline & Spontaneous & $18(47,4 \%)$ \\
\hline \multirow[t]{2}{*}{ Appearance } & With defecation & 17 (44,7\%) \\
\hline & Both & $3(7,9 \%)$ \\
\hline \multicolumn{2}{|l|}{ Analytical variables( $n=38)$} & Frequency \\
\hline \multirow{2}{*}{\multicolumn{2}{|c|}{$\begin{array}{l}\text { Haemoglobin }(\mathrm{g} / \mathrm{l}) \\
\text { Transfusion requirements }\end{array}$}} & $9,5(5,4-13,8)$ \\
\hline & & $12(31,6 \%)$ \\
\hline \multicolumn{2}{|l|}{ Endoscopic variables $(n=38)$} & Num. (\%) \\
\hline & A & $8(21,1 \%)$ \\
\hline \multirow[t]{2}{*}{ Proctitis grade } & $\mathrm{B}$ & $12(31,5 \%)$ \\
\hline & C & $18(47,4 \%)$ \\
\hline \multirow[t]{2}{*}{ Injure extension } & More than $10 \mathrm{cms}$ & $18(47,4 \%)$ \\
\hline & $\leq 10 \mathrm{cms}$ & $20(52,6 \%)$ \\
\hline \multirow{2}{*}{ Affected mucosa (circumference \%) } & More than $50 \%$ & $13(34,2 \%)$ \\
\hline & $\leq 50 \%$ & $25(65,8 \%)$ \\
\hline \multirow{2}{*}{ Friability } & No & $19(50 \%)$ \\
\hline & $\mathrm{Si}$ & $19(50 \%)$ \\
\hline
\end{tabular}


Table 3 Number of implemented sessions with APC to solving bleeding

\begin{tabular}{llllllll}
\hline $\begin{array}{l}\text { Number of Sessions to Achieve } \\
\text { Bleeding Resoluteness }\end{array}$ & I & 2 & 3 & 4 & 5 & 6 & 8 \\
\hline Number of patients & I & 16 & II & 4 & 3 & 1 & 2 \\
$\begin{array}{l}\text { Total sessions: } 105 \\
\text { Mean and range of sesions: } 3, \mathrm{I}(\mathrm{I}-8)\end{array}$ & & & & & & \\
\hline
\end{tabular}

The patients' haemoglobin increased after the treatment from $9.5 \mathrm{~g} / \mathrm{L}$ to $11.4 \mathrm{~g} / \mathrm{L}$. These different ranges were very statistically significant $(\mathrm{p}=0.000)$ (Table 4). Table 5 shows an evaluation of the relation between the number of sessions with APC to achieve the bleeding resolution and some variables of the study. First of all, Spearman bivariable correlation test was used to evaluate the relation between the variables haemoglobin and the number of therapeutic sessions with APC needed for the bleeding resolvability. The inverse relation between those variables was well-appreciated. Nevertheless, this correlation is weak, not significant $(\mathrm{p}>0.05)$. After that, Kruskal Wallis test was used to evaluate the association between the variables bleeding grade and the type of proctitis with the number of therapeutic sessions with APC. Researchers did not observe statistically significant association between those variables $(\mathrm{p}<0.05)$.

Table 4 Initial haemoglobin and haemoglobin after endoscopic therapy

\begin{tabular}{llll}
\hline Hemoglobin & Mean $(\mathbf{g} / \mathbf{l})$ & Paired t Student & $\mathbf{P}$ \\
\hline Initial & 9,5 & $-7,407$ & 0,000 \\
After Therapy & $1 \mathrm{I}, 4$ &
\end{tabular}

Table 5 Correlation between the number of sessions with argon plasma and the study variables

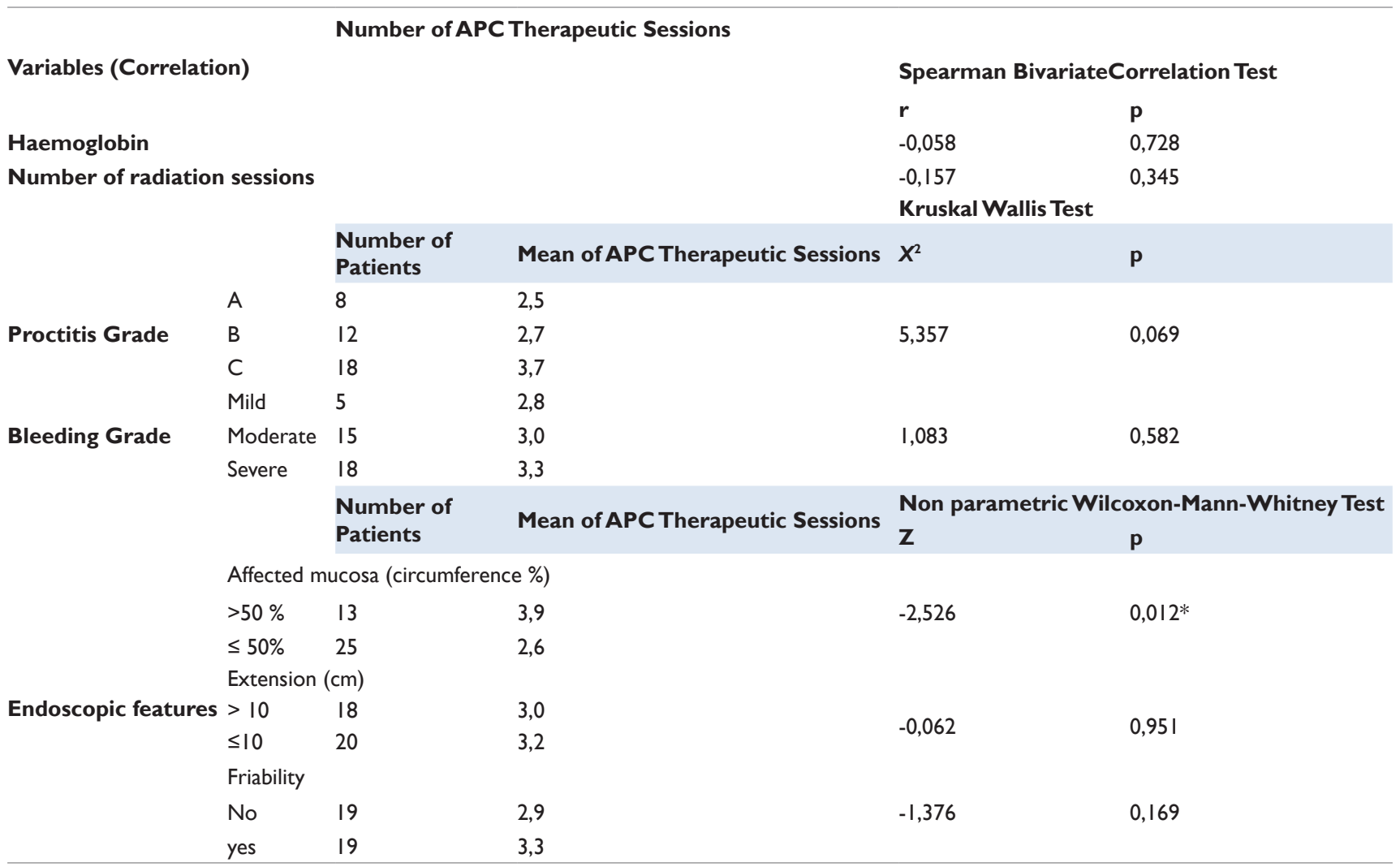

Finally, Wilcoxon-Mann-Witney parametric test was made to contrast following variables with the number of therapeutic sessions received:

a. Injure extension in $\mathrm{cm}$,

b. Percentage of affected circumference,

c. Presence of friability in relation.

It was found out that the significant association was noted between the percentage of affected mucusal and the number of the therapeutic sessions of argon used, giving a result that a major number of sessions was necessary for those patients with more than $50 \%$ of affected mucosal circumference. There was no evidence to suggest a statistically significant association between the rest of the variables studied and the number of therapeutic sessions of Argon plasma used.

\section{Discussion}

The age average higher than 60years is the expression of the major frequency of neoplasic diseases as the age is moving on. With the years, there is an existence of major exposition to carcinogens, and 
more probability of appearance of errors in the inactivation of protooncogenes and tumor suppressor genes control. The accumulation of these conditions gives the possibility of the biggest frequency of malignancy. The reviewed articles shows age average similar to this investigation. ${ }^{19,20}$

The higher frequency of women in this study corresponds to that the cervix and endometric cancer is one of the main indications of radiotherapy in the pelvic cavity and therefore greatly affects the rectum generating radiation proctitis. Gynecological cancer represents one of the main causes of cancer among female population in Cuba. ${ }^{21}$ In this research the sum of cervix cancer and the endometric cancer accounted more than three-quarter parts of the total sample; however, the study of Tormo et al., ${ }^{19}$ showed a higher prevalence of prostate cancer; they reported predominance of male population. These results are similar to those founded in the study of Zinicola et al., ${ }^{20} \&$ Latorre et al., ${ }^{5}$ Meanwhile de la Serna et al., ${ }^{22}$ had a coincidence criteria with our research, because the female population was their predominant sample.

The diseases that affect microvasculature are associated with the radiation proctitis due to they can influence on the injuries become more serious with a severe clinic expression. In this investigation, Hypertension and diabetes mellitus were the predominant microvascular disease. Tormo et al., ${ }^{19}$ reported the diabetes and squeamish cardiopathy prevalence. Latorre et al., ${ }^{5}$ describe that only $62.3 \%$ of their patients had some diseases which affected the microvasculature. About this point of view lots of studies do not make any references; however, it is thought these conditions increase the risk to develop later complications or more severe symptoms. ${ }^{2,4,23}$

The amount of radiotherapy sessions received by patients who developed radiation proctitis is described in the present study. Nevertheless, in the studied references the relation between the exposition to the radiations and the development of the radiation proctitis is established upon dose of radiotherapy expressed in values Gy. ${ }^{23-15}$ The details are not known by patients; they are not reported in the referenced documents. The data known and reported is the total amount of received sessions, which was described to evaluate its possible relation with the number of APC sessions needed to achieve the bleeding resolvability; however a significant association was not found.

The average time in months between the start of radiation and the beginning of symptoms is well-collected in different referenced literature. Zinicola et al. ${ }^{20}$ described an average of 25.4 months with a rank that varies between 6 and 120months. Similar reports were made by La Serna et al., ${ }^{22} \&$ Dees et al., ${ }^{26}$ with an average of 23.4 months and 22.5 months, respectively. All these values show a longer time between the end of radiation sessions and the appearance of symptoms, than those reported in our study. Clinic characteristics of patients with radiation proctitis was another analyzed theme in multiple researches. Zinicola et al., ${ }^{20}$ found out that before the endoscopic therapy of 14 patients, only 4 were affected by an often daily bleeding and 3 of them needed transfusion therapy. These results are similar to those shown in this actual investigation, although here it is said about the frequency, not about the severity of the episode. Latorre et al., ${ }^{5}$ had a predominance of cases with moderate bleeding, while Dees et al., ${ }^{26}$ reported daily bleeding in all patients (50), 13 had anemia and 6 needed transfusions. It is very important to make a previous analysis before endoscopic therapy, because the evaluation of the improvement of this parameter is a direct marker of the efficacy of the APC therapy. ${ }^{27}$ The necessity of transfusion is correlated with the haemoglobin value. Authors as Tam et al., ${ }^{28}$ referred that the percentage of patients needed

\section{transfusion varies between $10 \%$ and $25 \%$.}

Tormo et al., ${ }^{19}$ described a haemoglobin mean of $11.5 \mathrm{~g} / \mathrm{dl}$ (range 10.9 to 13 ), higher values than those of the current study. Zinicola et al, ${ }^{20}$ reported that of 14 patients 3 had severe anemia and needed transfusion. Latorre et al., ${ }^{5}$ reported haemoglobin mean values of $11,3 \mathrm{~g} / \mathrm{L}$. All these data show higher than those found in the present study, where the haemoglobin average was below $10 \mathrm{~g} / \mathrm{L}$. Endoscopic features of radiation proctitis has been studied; it was determinated factors that can predict the efficacy of endoscopic treatment. Latorre et al., ${ }^{5}$ found a great number of cases with less of $50 \%$ of the circumference of the rectum affected, results similar to the present study; This same group of researchers also found that 29 of 38 patients $(76.3 \%)$ showed mucosal friability, higher value than the value of our report. It was not possible compare the injury extension due to the form to report this data through the media of length.

Zinicola et al., ${ }^{20}$ showed in their study that the half of the sample presented a proctitis grade A, followed by cases with a grade B and $\mathrm{C}$, results that are contradictory to all those found in our study, where cases of proctitis grade $\mathrm{C}$ were the predominant ones. Authors like Canard et al., ${ }^{29}$ usually assess the severity of lesions according to the extension in centimeters, the intensity of the symptoms and the necessity of transfusion, parameters have been analyzed and discussed in this research.

Tormo et al., ${ }^{19}$ used an average of 2 APC sessions with a range between 1 and 4 . The results were below to those reported in this series, where the average got over 3 sessions per patient. In other way, Tam et al., ${ }^{28}$ and Tjandra et al., ${ }^{30}$ described a treatment response between 2 and 3 sessions made with a small number of complications, similar to our data. Latorre et al., 5 also reported an average of over 3 sessions; however, de la Serna et al. ${ }^{22}$ lower values according to the number of APC sessions (mean of 1.9, range 1-4 sessions). Zinicola et al., ${ }^{20}$ reported a mean of 1.5 sessions per patient.

It is very important to know the initial value of haemoglobin before the first APC session, it is essential to make an accurate assessment of the patient. Firstly, because the anemia brings a serious bleeding, so this is a right sign to make an endoscopic therapy, and secondly, because the increase of the haemoglobin values is a good parameter which shows the treatment efficacy. ${ }^{19}$ Tjandra et al., ${ }^{30}$ and Ravizza et al., ${ }^{31}$ reported an increase of the haemoglobin mean level that varies between 3-4 mg/dl after treatment ending; in our research the mean recovery of these values was $1.9 \mathrm{~g} / \mathrm{dl}$. Latorre et al., ${ }^{5}$ reported a haemoglobin recovery from $11.3 \mathrm{~g} / \mathrm{dL}$ to $14.01 \mathrm{~g} / \mathrm{dL}$ with the completion of treatment. De la Serna et al., ${ }^{22}$ showed an improvement of hemoglobin values of 1.5 and $1.9 \mathrm{~g} / \mathrm{dl}$; similar reports to the data were informed by the present research.

In our study only, a significant association was found. It was between the number of APC sessions and the percentage of affected circumference organ, which means: as more circumferential is the injury (injuries increased number of circumferentially settled), the necessity to implement many therapeutic sessions to achieve the hemorrhagic resolvability will be higher. Latorre et al., ${ }^{5}$ found a strong association between the percentage of affected mucus circumferentially and the number of therapeutics sessions when made a bivariable analysis to establish a relation between the endoscopic aspects and the APC sessions. They also found that the mucosal friability, in fact, was a variable that associated a major number of sessions .However, in this present work a strength of association to this variable was not found. The authors think if the endoscopic affection is high, so more serious could be in the clinic injury expression by radiation and the number of 
APC sessions to achieve the resolvability will be higher one. Similar results are reported by Taieb et al. ${ }^{32}$

Tjandra et al., ${ }^{30}$ evaluated the correlation between the number of APC sessions with the severity of bleeding, the level of haemoglobin and the proctitis extension. They only obtained a significant statistically result according to the proctitis extension in centimeters which was not demonstrated in our investigation. Nevertheless, the Tjandra's group did not take into account other endoscopic variables that maybe, have more influence on the assessment of the severity of the injury and the time of minimum endoscopic treatment to eliminate radiation injuries and its clinical manifestations. Kaessis et al., ${ }^{33}$ made a similar study as Tjandra et al., ${ }^{30}$ taking into account, as associated variables the number of APC sessions, the injure extension in $\mathrm{cm}$, describing also both group that as more injuries, the possibility to make necessary sessions to eliminate rectum injuries will be high.

Complications of this therapy have been reported by many researchers, most of them agreeing that it is a safe procedure. In the present study, the complication percentage was low. They were slight complications, symptoms that were treated and solved fast and with little actions. Latorre et al., ${ }^{5}$ reported that their 38 patients had rectorrhaegy. They needed to be hospitalized in $1.4 \%$ of cases. Slight complications were appeared. Proctalgy was the predominant complication. Only 5 patients presented re-bleeding after 6 months of the treatment ending. These results are higher than those reported in this investigation. Canard et al., ${ }^{29}$ referred one case of massive rectorrhaegy, being necessary the use of transfusions and sclerotherapy.

Proctalgy was the only adverse effect reported post-treatment during the first sessionby two patients, which relieved in 5 days. In one of them, the pain was self-limiting and other needed oral analgesic treatment only. These data emphasize the safety of the method, due to their few adverse effects. In the reviewed articles ${ }^{32-35}$ is described by several authors that the frequency of this complication may range between $7 \%$ and $20 \%$. In the case of the patients studied and reported in this current research, the complications were auto-limited in the first week after the APC session. Ravizza et al., ${ }^{31}$ found that the proctalgy was the most frequent complication, appearing in the $14 \%$ of their patients. These authors reported the flow higher than 2Lper minute, independently of the strength and the time of sessions, which produce more complications.

Obtained data from the response of the therapy, show the great effectiveness to solve radiation proctitis symptoms with less amount of sessions, the lack of serious complications, as the low and autolimited frequency of slight complications. All these data gathered to the easy implementation of the used method and show the factivity of this therapeutic modality, its safety assurance that guarantee a high and best control of rectum complications associated to radiotherapy.

\section{Conclusion}

Argon plasma coagulation is a good therapy for radiation proctitis with bleeding resolution and the haemoglobin improvement with few therapeutic sessions and few adverse effects. The proctalgy was presented with an easy resolution. The major percentage of affected circumferential mucusa is associated to the great number of therapeutic sessions to achieve the injure resolvability and its manifestations.

\section{Conflict of Interests}

The authors declare no conflict of interest.

\section{Acknowledgements}

None.

\section{Funding}

None.

\section{References}

1. World Helath Organization (WHO). Estadísticas sanitarias mundiales 2015. Geneva: World Helath Organization (WHO); 2016.

2. Denton AS, Andreyev JJ, Forbes A, et al. Non surgical interventions for late radiation proctitis in patients who have received radical radiotherapy to the pelvis. Cochrane Database of Systematic Reviews. 2002;1:CD003455.

3. Phan J, Swanson DA, Levy LB, et al. Late rectal complications after prostate brachytherapy for localized prostate cancer. Cancer. 2012;115(9):1827-1839.

4. Cotti G, Seid V, Araujo S, et al. Conservative therapies for hemorrhagic radiation proctitis: a review. Rev Hosp Clín Fac Med $S$ Paulo. 2003;58(5):284-292.

5. Latorre Sánchez M, Sempere García-Argüelles J, Barceló Cerdá S, et al Valoración de la respuesta endoscópica al tratamiento con argón plasma en la rectitis actínica crónica. Rev Esp Enferm Dig.2008;100(10):619 624

6. Tagkalidis PP, Tjandra JJ. Chronic radiation proctitis. Review article. ANZ J Surg. 2012;71:230-237.

7. Rustagi T, Mashimo H. Endoscopic management of chronic radiation proctitis. World J Gastroenterol. 2012;17(41):4554-4562.

8. Hanson B, MacDonald R, Shaukat A. Endoscopic and medical therapy for chronic radiation proctopathy: a systematic review. Dis Colon Rectum. 2012;55(10):1081-1095.

9. Mendenhall WM, McKibben BT, Hoppe BS, et al. Management of Radiation Proctitis. Am J Clin Oncol. 2014;37(5):517-523.

10. Raman RR. Two percent formalin retention enemas for hemorrhagic radiation proctitis: a preliminary report. Dis Colon Rectum. 2007; 50(7):1032-1039.

11. Cullen SN, Frenz M, Mee A. Treatment of haemorrhagic radiationinduced proctopathy using small volume topical formalin instillation. Aliment Pharmacol Ther. 2006;23(11):1575-1580.

12. Barrera A, Mansilla J, Bannura G, et al. Tratamiento de la rectitis actínica hemorrágica con aplicación tópica de formalina al 4\%. Rev Chil Cir. 2011;63(4):394-398.

13. Bennett MH, Feldmeier J, Hampson N, et al. Hyperbaric oxygen therapy for late radiation tissue injury Cochrane Database of Systematic Reviews. 2016;4:CD005005.

14. Feldmeier JJ. Hyperbaric oxygen therapy and delayed radiation injuries (soft tissue and bony necrosis): 2012 update. Undersea Hyperb Med. 2012;39(6):1121-1139.

15. Clarke RE, Tenorio LM, Hussey JR, et al. Hyperbaric oxygen treatment of chronic refractory radiation proctitis: a randomized and controlled double-blind crossover trial with long-term follow-up. Int $J$ Radiat Oncol Biol Phys. 2008;72(1):134-143.

16. Leiper K, Morris AI. Treatment of radiation proctitis. Clin Oncol (R Coll Radiol). 2007;19(9):724-729.

17. Lenz L, Rohr R, Nakao F, et al. Chronic radiation proctopathy: A practical review of endoscopic treatment. World J Gastrointest Surg. 2016;8(2):151-160

18. Karamanolis G, Psatha P, Triantafyllou K. Endoscopic treatment for chronic radiation proctitis. World J Gastrointest Endosc. 2013;5(7):308312.

19. Tormo V, Wikman Jorgensen P, García del Castillo G, et al. Efectividad de la fulguración con argón plasma en el tratamiento de la proctitis actínica crónica. Rev Esp Enferm Dig. 2009;101(2):91-96. 
20. Zinicola R, Rutter MD, Felasco G, et al. Hemorrhagic radiation proctitis: endoscopic severity may be useful it guide therapy. Int $J$ Colorectal Dis. 2003;18(5):439-444.

21. Ministerio de Salud Pública (MINSAP). República de Cuba. Oficina Nacional de Estadísticas (ONE). Anuario Estadístico de Cuba 2015, edición 2016. La Habana. 2016

22. de la Serna Higuera C, Martín Arribas MI, Rodríguez Gómez SJ, et al. Efficacy and safety of argon plasma coagulation for the treatment of hemorrhagic radiation proctitis. Rev Esp Enferm. 2004;96(11):758-764.

23. Czito BG, Willett CG. Radiation Injury. In: Feldman M, Friedman LS, (Eds.), Sleisenger and Fordtran's Gastrointestinal and Liver Disease: Pathophysiology/Diagnosis/Management. Saunders Elsevier, Philadelphia, USA. 2010;pp.639-651.

24. Hauer-Jensen M, Wang J, Boerma M,et al. Radiation damage to the gastrointestinal tract: mechanisms, diagnosis, and management. Curr Opin Support Palliat Care 1(1): 23-29.

25. Ryu J, Winter K, Michalski JM, et al. Interim report of toxicity from $3 \mathrm{~d}$ conformal radiation therapy (3D-CRT) for prostate cancer on 3DOG/RTOG 9406 level III (79.2GY). Int J Radiat Oncol Biol Phys. 2002;54(4):1036-1046.

26. Dees J, Meijssen MA, Kuipers EJ. Argon plasma coagulation for radiation proctitis. Scand J Gastroenterol Suppl. 2006;243:175-178.

27. Chutkan R, Lipp J, Waye J. The argon plasma coagulator: a new and effective modality for the treatment of radiation proctitis (abstract). Gastrointest Endosc. 1997;45(4): AB27.
28. Tam W, Moore J, Schoeman M. Treatment of radiation proctitis with argon plasma coagulation. Endoscopy. 2000;32(9):667-672.

29. Canard JM, Vedrene B, Bors G, Clauce P, Bader R, et al. Treatment of radiation proctitis by coagulation: long term results. Gastroenterol Clin Biol. 2003;27(5):455-459.

30. Tjandra JJ, Sengupta S. Argon plasma coagulation is an effective treatment for the refractory hemorrhagic radiation proctitis. Dis Colon Rectum. 2001;44(12):1759-1765.

31. Ravizza D, Fiori G, Torvato C, et al. Frequency and outcomes of ulcers during argon plasma coagulation for chronic radiation índuced proctopathy. Gastrointest Endosc. 2003;57(4):519-525.

32. Taïeb S, Rolachon A, Cenni JC, et al. Effective use of argon pla.sma coagulation in the treatment of the severe radiation proctitis. Dis Colon Rectum. 2001;44(12):1766-1771.

33. Kaassis M, Oberti F, Burtin P, et al. Argon plasma coagulation for the treatment of hemorrhagic radiation proctitis. Endoscopy. 2000;32(9):673-676.

34. Villavicencio RT, Rex DK, Rahmani E. Efficacy and complications of argon plasma coagulation for hematochezia related to radiation proctophaty. Gastrointest Endosc. 2002;55(1):70-74.

35. Sait Dag M, Akin I, Abidin Ozturk Z, et al. The Efficacy and Safety of Argon Plasma Coagulation in Treatment of Radiation Proctitis. Biomed Res. 2013;24(1):36-39. 